\title{
Formation of a type 1 diabetes young adult patient and public involvement panel to develop a health behaviour change intervention: the D1 Now study
}

Mary Clare O'Hara ${ }^{1,2^{*}}$ D, Áine Cunningham ${ }^{3}$, Cameron Keighron ${ }^{4}$, Gary Allen ${ }^{4}$, Antony Caulfield ${ }^{4}$, Ciara Duffy ${ }^{4}$, Michelle Long ${ }^{4}$, Madeleine Mallon ${ }^{4}$, Monica Mullins ${ }^{4}$, Garret Tonra ${ }^{4}$, Sarah Simkin ${ }^{5}$, Lisa Hynes ${ }^{6}$, Máire O'Donnell², Molly Byrne ${ }^{7}$, Sean F Dinneen ${ }^{2,3}$ and the D1 Now Type 1 Diabetes Young Adult Study Group

* Correspondence:
MaryClare.OHara@hse.ie
'Research \& Development, Health
and Wellbeing Division, Health
Service Executive, Merlin Park
University Hospital, 2nd Floor, Block
A, Merlin Park University Hospital,
Galway H91 N973, Ireland
${ }^{2}$ School of Medicine, National
University of Ireland, Galway,
Galway, Ireland
Full list of author information is
available at the end of the article

* Correspondence:

${ }^{1}$ Research \& Development, Health and Wellbeing Division, Health Service Executive, Merlin Park A, Merlin Park University Hospital, Galway H91 N973, Ireland ${ }^{2}$ School of Medicine, National University of Ireland, Galway, Full list of author information is available at the end of the article

\begin{abstract}
Plain English summary
Many young adults with type 1 diabetes (T1D) find it hard to control their blood glucose levels. With lots of things going on in their lives, their diabetes is often not the most important thing to them. That means they do not always take care of their T1D, for example by going to clinic appointments. Young adults with T1D do not usually get the chance to make suggestions on how to improve diabetes services. Being involved could help young adults to shape the diabetes care services that support them.

Since 2014 a diabetes research team based in Galway has been looking at ways to improve how diabetes services are delivered to young adults. Eight young adults (aged 18-25 years) with T1D called the Young Adult Panel (YAP) are members of this team and have helped design the "D1 Now" intervention which aims to improve diabetes services.

The YAP came up with questions to ask other young adults with T1D, their families and friends and healthcare providers about their experiences of healthcare services and how these could be improved. The YAP also shared messages from the research at national conferences and on local radio. They helped with writing sections of a grant application to take this research work forward.

Our experience has shown the importance of involving young adults with T1D in helping to design research focusing on ways to improve their diabetes service that will help them and other young adults to live with diabetes in the future.

(Continued on next page)
\end{abstract}


(Continued from previous page)

\section{Abstract}

Background Research indicates that young adults (18-25 year olds) with type 1 diabetes (T1D) often disengage from health services and their general diabetes management. Involving young adults with T1D in co-designing research to develop a behaviour change intervention to improve engagement with health services could potentially improve overall self management and health. A local youth mental health organisation called Jigsaw, Galway developed a very successful model for involving users in service design and development. Based on this model, the aim was to form a Young Adult Panel (YAP) of 18-25 year olds with T1D and involve them in all aspects of a study to develop an intervention to improve health and wellbeing for young adults with T1D called D1 Now.

Methods Recruitment of young adults was achieved through a multimedia campaign. A consultation event was organised, followed by interviews with interested young adults. A panel of 8 members was selected. Following initial training for YAP members in committee skills and an introduction to different research methods and terms, YAP members participated in different stages of the research process. They were represented on the research study steering group and attended research meetings. They developed research materials, reviewed and interpreted research findings and helped develop the online platform to enhance engagement between young adults and their diabetes healthcare providers. They contributed to an international consensus conference on health services delivery for young adults with T1D and wrote specific sections of a further grant application to test out the new intervention.

Results As a direct result of the YAP, a meaningful dialogue has opened up between healthcare providers and young adults within the D1 Now research team. Their involvement has led to a better understanding of what needs to be achieved in order to improve health service delivery. They have been active members in co-designing a health behaviour change intervention to improve engagement between young adults with T1D and healthcare providers which will be evaluated in future research.

Conclusion Through the formation of the YAP, we have demonstrated that involving young adults with T1D in healthcare research is feasible and productive.

\section{Background}

The global incidence of type 1 diabetes (T1D) is increasing [1]. Traditionally diabetes research has focused on children, the transition period from paediatric to adult services and on older adults $[2,3]$. In the past few years there has been a growing focus on young adults with T1D who have transitioned to adult services and how best to improve their clinical and psychosocial outcomes. Young adulthood or emerging adulthood describes the years between 18 and 25 years old [4].

Young adults living with T1D throughout the world often experience poor outcomes. Reasons for this include poor knowledge and self management skills, high levels of psychosocial distress, poor clinic attendance, poor adherence with treatment recommendations and engaging in high risk behaviours [5-7]. A recent international comparison of glycaemic control among people with T1D highlighted that 15-24 year olds were most likely to have poor glycaemic control $\left(\mathrm{HbA}_{1 \mathrm{c}}\right.$ values over than $\left.58 \mathrm{mmol} / \mathrm{mol} /<7.5 \%\right)$, in comparison to both younger (less than 14 years) and older (over 25 years) cohorts with T1D [8]. Participants who submitted data to this comparison study were mainly 
from developed countries. A recent systematic review highlighted that the efficacy of existing interventions aimed at improving outcomes among young adults with T1D was inconclusive. The review also highlighted a lack of high quality, well designed studies in this area [9].

\section{Patient and public involvement in research}

Patient and Public Involvement (PPI) in research is growing internationally with initiatives and projects aimed at promoting such involvement being reported in the UK, Europe, the US, Canada and Australia [10-15]. The UK INVOLVE organisation which supports active public involvement in National Health Service, public health and social care research define PPI as research carried out 'with' or 'by' members of the public rather than 'to', 'about' or 'for' them [16]. The National Institute of Health Research (NIHR) in the UK funded by the Department of Health have committed to including "the public as partners in everything we do to deliver high quality research that improves the health, wellbeing and wealth of the nation" [17].

Whilst there is a moral and ethical argument for involving patients and public in health research and service delivery decisions that will affect them, there is also evidence that PPI makes interventions more effective and efficient. It has been shown that intervention development, service re-design, recruitment and retention of study participants and randomised controlled trials can benefit from PPI [18-21]. Many research funding programmes now request that PPI is included and is a genuine component in research applications [22-24].

A culture of PPI in Irish health research is also growing. The Irish Health Research Board in its Strategy 2016-2020 recognised the importance of PPI and PPI is now a feature of most of its funding calls [25]. They have also recently launched a PPI Ignite call, an institutional application focused on education, training and evaluation to promote a culture of PPI activity in health research in Irish higher education institutions [26]. The Irish Health Research Forum (IHRF), a collaboration of stakeholders aiming to influence health research in Ireland, published a succinct report on PPI stating that PPI occurs "when individuals meaningfully and actively collaborate in the governance, priority setting, and conduct of research, as well as in summarising, distributing, sharing, and applying its resulting knowledge" [27].

\section{PPI and young adults}

Over the past decade there has been a growing emphasis on involving children and young adults in health research, service design and decision-making processes [28-31]. Involving young adults in research processes from the outset will enable true participatory research [32]. There is no argument for not involving young adults in any part of the PPI process in which you would involve older adults. McDonagh and Bateman outline areas where young adults can make active and valuable contributions to PPI and to the overall health research process [33]. In the present study, the research team aimed to involve young adults as co-researchers in setting the research agenda, development of the protocol, design of the intervention, Advisory Board membership and dissemination [33]. However, unlike the McDonagh and Bate article, young adults in the present study would not also act as research participants. 


\section{D1 now}

Since 2014 a multidisciplinary research team based at the National University of Ireland, Galway (NUI Galway) and Galway University Hospitals (GUH) have been working to establish an evidence base from which to develop a new intervention, known as D1 Now. D1 Now aims to improve engagement between young adults with T1D and their healthcare providers and ultimately improve their self management and diabetes-related health outcomes. This work has been informed by the Medical Research Council guidelines for developing and evaluating complex interventions [34] and the Behaviour Change Wheel for characterising and designing behaviour change interventions [35]. The D1 Now study has five main work streams; (i) to conduct a systematic review of the current evidence in the area of young adults and type 1 diabetes (ii) to conduct a qualitative engagement study where young adults with T1D in Galway, Belfast and Dublin participated in focus groups and their friend/ family members and their healthcare providers participated in interviews (iii) to conduct a Discrete Choice Experiment (this approach is explained below in the PPI Training section) that asks young adults to rank their clinic preferences and (iv) to use all work streams to establish an evidence base from which to define a behaviour change intervention to improve outcomes for young adults. The final aim of this development phase was to form a PPI panel of young adults with T1D who would actively be involved in co-designing all aspects of the intervention. This paper aims to describe the formation and progression of this PPI panel.

\section{Methods}

\section{Background to PPI in the D1 Now study}

The D1 Now study was funded by the Health Research Board (in Ireland) Ethical approval was granted by the relevant local research ethics committees in NUI Galway, St. Vincent's Healthcare Group Ethics and Medical Research Committee, Dublin and Royal Victoria Hospital, Belfast where the research was undertaken. Written consent was obtained from all research participants. Ethical approval was sought and granted for the main D1 Now study (developing a new behaviour change intervention to improve outcomes for young adults with T1D) but not for the formation of the PPI panel itself because the PPI panel were recruited as co-researchers as opposed to research participants. However, stakeholders were cognisant of the fact that the PPI panel did not have experience in research so careful consideration was given to ensuring that interactions between the stakeholders and the young adult PPI panel were respectful, considerate and professional at all times. One of the aims of the study design was to establish a PPI panel of young adults living with T1D. In writing the initial grant application, one young adult living with T1D was involved as a collaborator and contributed to pre-grant writing and brainstorming meetings along with the rest of the research team. This young adult was attending the diabetes service in Galway and was also completing a Masters in Health Economics at the time. He approached the research team (SD and $\mathrm{MCOH}$ ) about getting involved in the study and bringing a service user perspective to the team. Once funding for the D1 Now study was secured, the research team began forming a PPI panel of young adults with T1D in the west of Ireland. 


\section{The Jigsaw model}

Jigsaw is the National Centre for Youth Mental Health in Ireland. It's mission is to bring about significant change in how Ireland thinks about, responds to and supports young people's mental health [36-38]. At the time of publishing, there are 13 Jigsaw Services across Ireland providing early intervention supports to young people. Youth participation is a guiding principle of Jigsaw's work and is a central feature of the design and planning of all Jigsaw projects $[39,40]$. Jigsaw is closely guided in strategy and decision-making by a nationwide network of over 130 Youth Advisors, aged between 16 and 25. They help guide decision making, recruit staff members and inform research, ensure Jigsaw is relevant to those they aim to support and are central to Jigsaw's work in reducing the stigma that surrounds mental health. Since 2013 a strong link has been forged between Jigsaw in Galway and the diabetes research team. This collaboration involves mutual engagement. Jigsaw personnel (SS) provides advisory and practical roles, including a venue, guidance regarding effective engagement of young people and expert co-facilitation of YAP meetings. In turn, staff members from the research team have facilitated diabetes education training for Jigsaw staff. The diabetes research team adapted the Jigsaw model of involving young people (16-25 years) to develop a PPI panel in young adult (18-25 years) T1D research.

\section{Involving young adults in PPI recruitment process}

A Diabetes Nurse Specialist (DNS) initially identified 3 young adults (18-25 years) attending routine clinic appointments who were interested and enthusiastic about the possibility of being involved in research. Three preparatory meetings took place from June 2013 and January 2014 in Jigsaw, expertly facilitated by its Project Manager (PM), and the DNS (ÁC). The aims and objectives were explained to the 3 young adults and they were asked to generate some ideas of how best to recruit a PPI panel. Figure 1 illustrates the recruitment process involved in forming the PPI panel.

The young adults thought that an open consultation event should be organised. They penned a general letter to young adults with T1D attending the clinic in Galway asking them to attend this consultation event if they were interested in getting involved as coresearchers with the D1 Now research team. Diabetes centre staff took responsibility for posting these letters and 50 letters in total were sent to young adults who were randomly selected from the diabetes centre's clinical database. The 3 young adults also helped develop promotional flyers used in local media, Twitter and Facebook campaigns. Diabetes Ireland (the Irish diabetes charity) also posted the flyer on their website. These were alternative approaches to broaden the search and not limit recruitment to those who attend the clinic.

\section{Consultation process}

The open consultation event was held in Jigsaw on 19th February 2014. It was facilitated by Jigsaw's PM (SS) and the DNS (ÁC). The young adults who attended the event were split into 3 groups of 6-7 people ( $n=19,10$ were female). Each group was asked to nominate 2 people to feedback their discussions to the larger group. Figure 2 is the diagram that was used to facilitate an ice-breaker and general discussion around the topic of living with T1D and how this relates to other aspects of young adulthood. Pre-determined open topics were agreed ahead of time to guide an open and fruitful discussion (Table 1). 


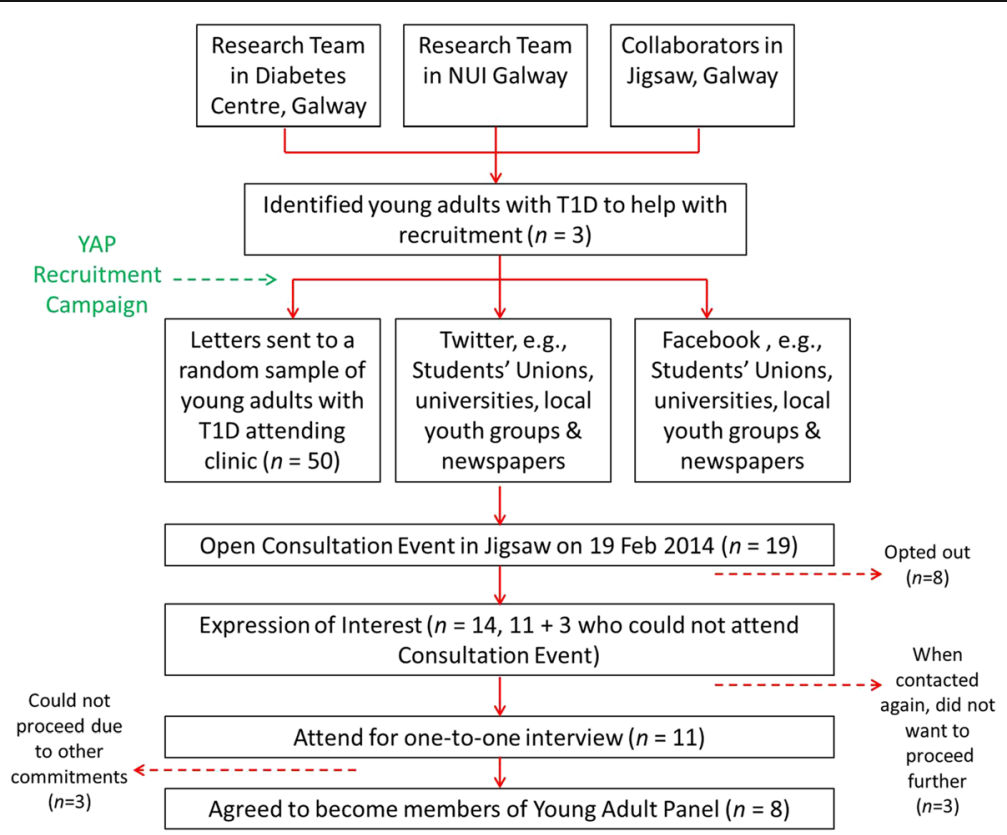

Fig. 1 Recruitment and consultation process involved in forming the YAP

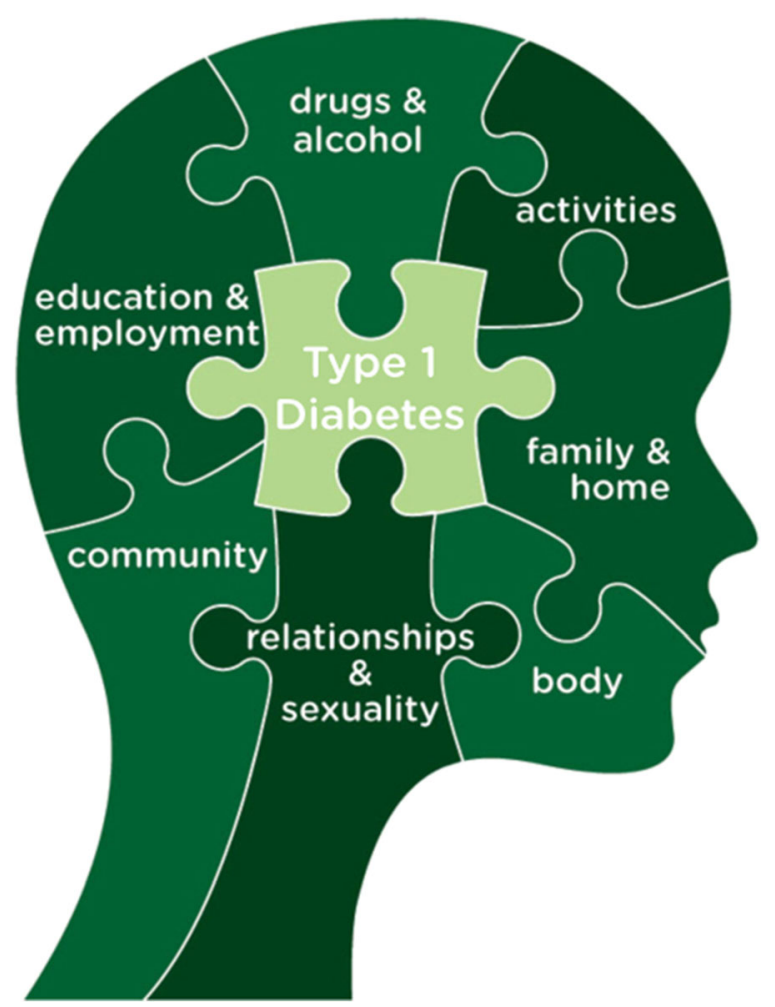

Fig. 2 Diagram used during consultation event to facilitate an ice-breaker and discussion around the topic of living with T1D and how this relates to the other aspects of young adulthood 
Table 1 Topics used during the Consultation Event to generate an open discussion

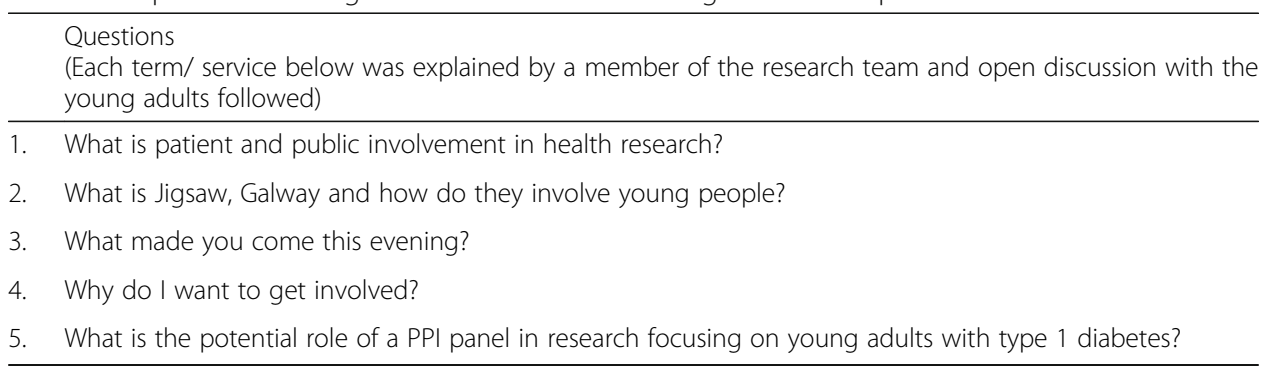

Eleven young adults expressed an interest in participating in the PPI panel (of the 19 who attended). In addition, there were a further 3 young adults who expressed an interest but could not make the event. A guide for YAP membership was adapted by Jigsaw Galway (Table 2) in order to inform the selection process, to establish a common understanding among stakeholders and to enable informed consent by the young adults. The Jigsaw PM (SS) and lead researcher ( $\mathrm{MCOH}$ ) organised one-to-one interviews with everyone who expressed an interest to ensure each of the young adults fully understood what was being asked of them and the commitment involved. In turn, it provided the young adults with an opportunity to ask the research team questions. When contacted again to arrange an interview time, 11 (of the 14) wanted to proceed further. Following this process, 8 young adults (CK, GA, AC, CD, ML, MM, MM and GT) were offered a place on the PPI panel ( 3 males and 5 females). In consultation with the other 3 young adults it was decided that the time was not right for them to join

Table 2 Terms of reference, roles and responsibilities developed by and for the Young Adult Panel

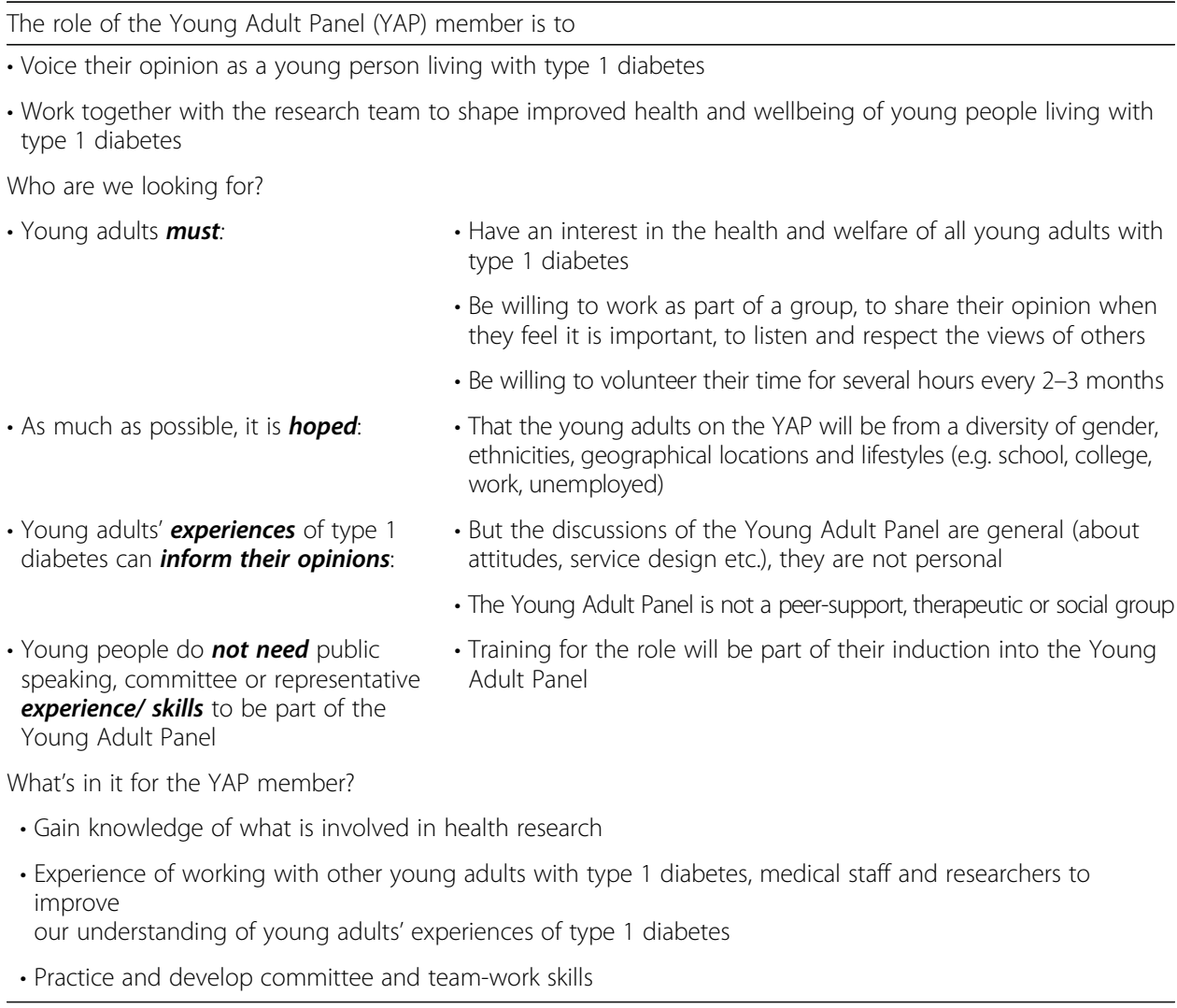


due to other commitments (study/ work) that would make it difficult for them to attend meetings. All YAP members were between 18 and 25 years old. During the consultation phase it was explained to potential YAP members that there were insufficient funds in the study budget to pay for their time but that they would be reimbursed for any out-of-pocket travel expenses and all meetings would provide catering.

\section{PPI panel training}

The first PPI panel meeting took place on May 29, 2014 in Jigsaw. It was facilitated by Jigsaw's PM (SS) and the lead researcher $(\mathrm{MCOH})$. Following an ice-breaker session, the young adults were asked to agree a name for the PPI panel. After much debate they decided on the name of Young Adult Panel (YAP). They felt it represented them and their involvement, without labelling them as 'diabetics'. Following the Jigsaw, Galway model, the membership guide was adopted as a terms of reference for the YAP (Table 2) and ground rules were developed and agreed. A discussion on 'Hopes, Fears and Expectations' regarding their participation also took place. They discussed issues around confidentiality and time commitment. Finally, a schedule of training meetings was agreed for the summer 2014. The YAP members decided when, where and duration of meetings and what type of food would be provided at these meetings. It was agreed that an online meeting scheduling tool, Doodle, would be used to arrange meetings and if more than 4 members could not attend any meeting, it would be cancelled and re-scheduled. Members agreed to communicate between meetings via email, text messages and a private Facebook group. These forums only included the 8 members of the YAP and the lead researcher $(\mathrm{MCOH})$.

A broad range of training sessions were designed and delivered for YAP members. The training sessions reflected the necessary skills for an effective committee, as well as the knowledge required to understand and contribute to the research, such as qualitative research and health economics. The following is a list of training provided to YAP members during the summer of 2014 and as the study progressed:

- Committee skills

- The organisational structure of the research team

- Team-building skills

- Introduction to research methods and terminology

- Introduction to qualitative research

- The format of peer reviewed scientific papers and the basics in interpreting them

- Presentation skills

- Basic introduction to health economic methodology, specifically Discrete Choice Experiments (DCE). DCE is a technique commonly used in health economics to elicit patient preferences for healthcare services. A DCE is an attribute-based measure of benefit; attributes could include waiting times, health services providers available at a particular clinic, when appointments was scheduled (for example weekday or weekend days). The DCE model is based on the assumption that healthcare services can be described by their attributes and an individual's valuation depends upon the levels of these attributes [39]. 
- Introduction to the think-aloud technique [40] and brainstorming. These were approaches used in many meetings. Both techniques are closely aligned. Brainstorming is a process for generating creative ideas and solutions through in-depth discussion and debate. The think-aloud technique enables even deeper discussions as it encourages people to verbalise everything they can think of in relation to a given topic, with reference to a tool or product, like a draft survey. In this way the think-aloud technique facilitated the development of research materials by simulating real-world use of those materials to generate practical feedback and solutions.

- Introduction to the role of technology in diabetes self management

The majority of the training was delivered by the lead researcher $(\mathrm{MCOH})$ with specific sessions being facilitated by an expert in qualitative research, Jigsaw's PM (SS), a health economist and an expert in strategic marketing. YAP members were invited to opt-in to a range of other workshops that Jigsaw frequently facilitate including public speaking, interviewing, and understanding youth mental health.

\section{Ensuring quality involvement and communication}

According to guidance in establishing effective PPI, it was important to establish a good working relationship between YAP members and the rest of the research team $[41,42]$. This was created by scheduling face-to-face meetings and maintaining an open discussion on emails and Facebook between meetings. Both members of the YAP and the rest of the research team were ensured a voice at the meetings and all opinions were listened to. Some YAP members contributed more opinions than others, especially in the earlier meetings but the facilitator ensured that each member was given an opportunity to contribute. The facilitator would continually invite 'quieter' members of the group to share their opinions and solutions. As the group become more familiar with each other, there was a more balanced representation from all YAP members. Facilitation of meetings, the planning of research and other communications by Jigsaw's PM (SS) ensured the ethos of PPI became integrated into the research and the workings of all members of the research team. The lead researcher $(\mathrm{MCOH})$ made her contact details available to YAP members and encouraged them to get in touch with her if they had any queries or difficulties. This built trust and confidence in working together and created a sense of co-ownership of the study. Social events were organised to maintain everyone's motivation and enthusiasm (all YAP members were invited along with 3-4 members of academic research team). In total, 3 social events were organised, including going to an indoor activity centre, going for a meal and going to a quiz night. During the course of the study some YAP members asked the clinical research team to write letters of recommendation, help them with their curricula vitae and assist them entering academic competitions. The research team were delighted to be asked and assisted YAP members wherever was possible and appropriate. This also strengthened motivation, trust and involvement. YAP members were also made aware of other events that they might find interesting or useful, e.g., events for World Diabetes Day, locally organised activities for people with type 1 diabetes. YAP members were regularly invited to give feedback 
on their involvement. The research team recognised the time, involvement and commitment the YAP members provided. Although YAP members were not paid for their time in this project, all out-of-pocket expenses were covered including costs associated with catering for meetings, travel, subsistence, poster printing and conference attendance.

\section{Results}

Formation of the 8 member YAP was the foundation on which this study was based and the first action to be completed before work began on the other work streams. The activities of the YAP ran parallel to all other work streams. YAP members contributed to all objectives of the D1 Now development study including input into the naming of the study and its logo. In line with current PPI guidance and the Jigsaw model, it was important from the outset that YAP members felt involved in the research process and this was established at their first meeting where they agreed a name, terms of reference and ground-rules. The YAP was comprised of 3 male and 5 female members aged between 18 and 25 years. YAP members are from Counties Galway, Clare, Sligo, Meath and Donegal and only 3 received their diabetes care in Galway. Four YAP members were in third-level education and the remaining members were in full- or part-time employment. The composition of the YAP demonstrates the success of the recruitment strategy in reaching young adults from a diverse background and settings, interested in getting involved with health research. Over the course of the 30 month study, the YAP met with the lead researcher $(\mathrm{MCOH}) 18$ times with typically between 5 and 6 members attending each meeting. The research team tried to schedule meetings evenly throughout the course of the study. However, at times, meetings occurred in clusters as deadlines arose, e.g., finalising topic guides to begin the qualitative engagement study. Meetings at the start of the study were normally scheduled for approximately $2 \mathrm{~h}$ with overly ambitious agendas. The first 4 meetings over-ran. As the academic research team worked more closely with the YAP members, meetings were shortened to include only 1-3 agenda items and usually lasted $1 \mathrm{~h}$. This proved more successful, productive and acceptable.

As well as meeting as a group, the YAP elected 2 members who would sit on the study's Steering Group and 2 members who would sit on the study's Knowledge Exchange and Dissemination Scheme (KEDS) Group.

Table 3 details where YAP members led contributions throughout the study.

Table 3 Contributions led by YAP members

- Development of the topic guides that were used in focus groups and interviews with 3 key stakeholders groups in 3 study sites across Ireland and Northern Ireland; (i) young adults living with T1D, (ii) diabetes healthcare professionals (HCP) and (iii) friends and family members of young adults with T1D.

- Reviewing and interpreting findings from the systematic review conducted by other members of the research team.

- Development of participant materials used during the study, e.g., letters of invitation, consent forms, participant information sheets and recruitment materials.

- Development of 2 discrete choice experiments on clinical preferences and preferences for peer/ social support outside of routine clinic visits.

- Dissemination of findings at national conferences (Table 4).

- On naming of the study (D1 Now) and its logo 
YAP members contributed and inputted into the following throughout the study:

- Input into the development of an online platform to enhance engagement between young adults with T1D and their diabetes team.

- Contributed to the coordination and hosting of a 3-day international consensus conference in Galway, called Strength in Numbers, June 2016.

- Wrote specific sections of a grant application that the research team submitted in July 2016, e.g., lay summary and the PPI section.

- Contributed to other sections of the same grant application, e.g., sections on studies within a trial (SWAT) and knowledge exchange and dissemination.

- Supported and promoted study updates and announcements on social media, e.g., retweeting posts on Twitter, liking and re-posting announcements on Facebook.

- Wrote the Plain English Summary of this paper and commented on its overall content.

Feedback from the YAP and through their engagement in the activities listed above demonstrates that panel members feel co-ownership of the design and development of the new intervention. Feedback from the academic research team highlights their perceptions of the invaluable role played by the YAP in conducting this research. Contributions by the YAP and other young adults with T1D at the 3-day international conference organised as part of the development study's activities was described in delegate feedback as the "greatest strength of the event". PPI, guided by current recommendations and local expertise, significantly contributed to the achievement of the aims of this research, enriched the activities of the academic research team, empowered the YAP members to influence research related to them and their peers and facilitated the development of a protocol for an innovative behaviour change intervention.

\section{Discussion}

There has been a shift in recent years not only to focus research efforts in the area of young adults with T1D but also to involve this group in the research process to better address the complex factors influencing self management and wellbeing [43-45]. It is recommended to involve young adults in all appropriate PPI processes and stages [31-33]. The D1 Now study team has demonstrated that it is feasible and beneficial to include a PPI panel of young adults with T1D in health research. Forming the YAP required buy-in from both panel members and the rest of the research team. YAP members had to feel valued, listened to and confident, while researchers had to relinquish some control in order for the opinions, concerns and solutions of the YAP to be heard. The process of understanding and integrating the ethos of PPI occurred over the course of the study, as trust, communication and an open dialogue was established through team interaction and discussion.

The study team encountered many of the common challenges in forming and progressing its PPI panel [46, 47]. The majority of barriers were successfully overcome with the guidance of the Jigsaw team, and group problem-solving and discussion. Forming and facilitating the YAP involved a substantial amount of administrative time by the lead researcher $(\mathrm{MCOH})$ and a significant time commitment from YAP members, on a voluntary basis. The research process can be perceived as slow and progress can be perceived as tedious by members of the public. Jigsaw's PM (SS) was skilled in managing expectations (YAP members' and researchers'), e.g., not all ideas are feasible and not all can be readily implemented but rather 
open dialogue ensures that ideas are given meaningful consideration. Researchers had to avoid acronyms, abbreviations and research jargon and YAP had to be confident to ask if they did not understand something. YAP members are all living with T1D. During the course of the study it was important to realise that they are invested and care about being involved in this process and it was important for the research team to listen and value what they were saying. There was a concern that members of the YAP, particularly those who attend GUH, might hold-back about their experiences and opinions as they would not want to offend the diabetes care team but this was not evident during the study. PPI research raises important issues related to the provision of patient care and involvement in research of those receiving care. Open dialogue and responsiveness to issues enabled the research team in this study to recognise and address these issues.

In line with current recommendations, in September 2016, an independent researcher commenced a qualitative study aimed at measuring the impact of the YAP on the D1 Now development study [47]. Interviews have already been conducted with both members of the YAP and the rest of the research team. A content analysis approach will be used to evaluate minutes from meetings, think-aloud sessions, brainstorming sessions and the contribution of the YAP to the study's dissemination activities (Table 4).

Since April 2017, the D1 Now Study team has been funded by a HRB Definitive Intervention and Feasibility Award (HRB Ref: DIFA-2017-034). The team has now embarked on the next phase of the study, to conduct a feasibility and randomised pilot study of the intervention. The YAP were the first PPI panel to be recognised as official collaborators by the HRB and the comments from the award's international peer reviewers were positive, one reviewer commented that there was "robust and meaningful inclusion of patient perspectives via Young Adult Panel" and a "track record of meaningful engagement with patients". Since the award was made, the YAP has been rejuvenated, existing members were asked if they wished to remain involved or 'graduate' from the study (5 opted to stay involved) and a campaign (similar to that described above) was undertaken to recruit new members (5 new members have joined the YAP). The YAP currently stands at 10 members indicating that it is sustainable, acceptable and meaningful to both young adults with T1D and members of the academic research team.

\section{Limitations}

The YAP consisted of only 8 members and as such was not a representative group of young adults living with T1D in Ireland (please see Fig. 1 and the first paragraph of the Results section). While all out-of-pocket expenses and all involvement expenses were reimbursed for YAP members, there were inadequate resources in the approved budget to pay members for their time. This may have negatively impacted on those who would have liked to have been involved but could not because of the cost constraints. While INVOLVE recommend an hourly rate paid to PPI members [12], other financial barriers in paying patients for their involvement in research (e.g., should payment come under personnel costs in the budget or under running costs), will need to be addressed in future studies [48].

\section{Conclusions}

Involving young adults through a PPI panel has significantly contributed to all aspects of the study. The YAP felt co-ownership of the design and development of the D1 Now 
Table 4 Dissemination activities of the YAP

\begin{tabular}{|c|c|c|c|c|c|}
\hline & Title & Format & Forum & Venue & Date \\
\hline 1. & $\begin{array}{l}\text { Experiences of Patient } \\
\text { Involvement in the } \\
\text { Development of an } \\
\text { Intervention for Young } \\
\text { Adults with T1D: The D1 } \\
\text { Now Study }\end{array}$ & $\begin{array}{l}\text { YAP member co-authored } \\
\text { a blog (with lead } \\
\text { researcher) }\end{array}$ & $\begin{array}{l}\text { NUI Galway Health } \\
\text { Psychology Blog }\end{array}$ & NUI Galway & $\begin{array}{l}14^{\text {th }} \mathrm{Nov} \\
2016\end{array}$ \\
\hline 2. & $\begin{array}{l}\text { A systematic review of } \\
\text { interventions to improve } \\
\text { outcomes for young adults } \\
\text { with type } 1 \text { diabetes: } \\
\text { Towards the development } \\
\text { of a new intervention [15] }\end{array}$ & $\begin{array}{l}\text { YAP members (listed as } \\
\text { 'for the Irish Type } 1 \\
\text { Diabetes Young Adult } \\
\text { Study Group') contributed } \\
\text { towards the interpretation } \\
\text { of findings }\end{array}$ & Peer-reviewed journal & $\begin{array}{l}\text { Diabetic } \\
\text { Medicine }\end{array}$ & $\begin{array}{l}20 \text { Oct } \\
2016 \\
\text { [Epub } \\
\text { ahead } \\
\text { of print] }\end{array}$ \\
\hline 3. & $\begin{array}{l}\text { Strength in numbers: a } \\
\text { consensus conference to } \\
\text { reach agreement on a } \\
\text { novel approach to care } \\
\text { delivery for young adults } \\
\text { with type } 1 \text { diabetes }\end{array}$ & $\begin{array}{l}\text { Abstract that was co- } \\
\text { authored by all YAP } \\
\text { members was accepted } \\
\text { for poster presentation } \\
\text { and won the Pat Barron } \\
\text { Perpetual Trophy for } \\
\text { Education }\end{array}$ & $\begin{array}{l}9^{\text {th }} \text { West of Ireland } \\
\text { Integrated Diabetes Care } \\
\text { Conference }\end{array}$ & $\begin{array}{l}\text { Castletroy } \\
\text { Park Hotel, } \\
\text { Limerick }\end{array}$ & $\begin{array}{l}7-8 \text { Oct } \\
2016\end{array}$ \\
\hline 4. & $\begin{array}{l}\text { Understanding young } \\
\text { adults' preferences for } \\
\text { diabetes clinic care: A } \\
\text { discrete choice experiment } \\
\text { pilot study }\end{array}$ & $\begin{array}{l}\text { Abstract that was co- } \\
\text { authored by all YAP } \\
\text { members was accepted } \\
\text { for poster presentation }\end{array}$ & $\begin{array}{l}9^{\text {th }} \text { West of Ireland } \\
\text { Integrated Diabetes Care } \\
\text { Conference }\end{array}$ & $\begin{array}{l}\text { Castletroy } \\
\text { Park Hotel, } \\
\text { Limerick }\end{array}$ & $\begin{array}{l}7-8 \text { Oct } \\
2016\end{array}$ \\
\hline 5. & $\begin{array}{l}\text { Involving young adults in } \\
\text { research and service } \\
\text { design: The Young Adult } \\
\text { Panel }\end{array}$ & $\begin{array}{l}\text { YAP member was an } \\
\text { invited speaker (with } \\
\text { Jigsaw's PM) }\end{array}$ & $\begin{array}{l}\text { Strength in Numbers: } \\
\text { Teaming up to improve } \\
\text { the health of young } \\
\text { adult with type } 1 \\
\text { diabetes } 3 \text {-day } \\
\text { international consensus } \\
\text { conference }\end{array}$ & NUI Galway & $\begin{array}{l}22-24 \\
\text { Jun } \\
2016\end{array}$ \\
\hline 6. & $\begin{array}{l}\text { Re-Imagining Young Adult } \\
\text { Diabetes Care }\end{array}$ & $\begin{array}{l}\text { YAP member was an } \\
\text { invited speaker (with the } \\
\text { grant holder) }\end{array}$ & $\begin{array}{l}\text { PPI in Research } \\
\text { Conference: working as } \\
\text { partners, making a } \\
\text { difference }\end{array}$ & $\begin{array}{l}\text { Westwood } \\
\text { Hotel, } \\
\text { Galway }\end{array}$ & $\begin{array}{l}27^{\text {th }} \text { Apr } \\
2016\end{array}$ \\
\hline 7. & $\begin{array}{l}\text { The involvement of the } \\
\text { type } 1 \text { diabetes Young } \\
\text { Adult Panel in the 3-day } \\
\text { international Strength in } \\
\text { Numbers conference }\end{array}$ & $\begin{array}{l}\text { YAP member was invited } \\
\text { to do a radio interview }\end{array}$ & $\begin{array}{l}\text { The Keith Finnegan } \\
\text { Show }\end{array}$ & $\begin{array}{l}\text { Galway Bay } \\
\text { FM }\end{array}$ & $\begin{array}{l}26^{\text {th }} \text { Apr } \\
2016\end{array}$ \\
\hline 8. & $\begin{array}{l}\text { Formation of a type } 1 \\
\text { diabetes young adult } \\
\text { panel as an example of } \\
\text { patient involvement in } \\
\text { research }\end{array}$ & $\begin{array}{l}\text { Abstract that was co- } \\
\text { authored by all YAP } \\
\text { members was accepted } \\
\text { for oral presentation }\end{array}$ & $\begin{array}{l}20^{\text {th }} \text { Annual Foundation } \\
\text { of European Nurses in } \\
\text { Diabetes Conference }\end{array}$ & $\begin{array}{l}\text { Stockholm, } \\
\text { Sweden }\end{array}$ & $\begin{array}{l}11-12 \\
\text { Sep } \\
2015\end{array}$ \\
\hline 9. & $\begin{array}{l}\text { Formation of type } 1 \\
\text { diabetes Young Adult } \\
\text { Panel in health research }\end{array}$ & $\begin{array}{l}\text { Abstract that was co- } \\
\text { authored by all YAP } \\
\text { members was accepted } \\
\text { for oral presentation and } \\
\text { made it to semi-final stage }\end{array}$ & $\begin{array}{l}\text { Threesis Competition } \\
\text { (academic challenge to } \\
\text { present research using } \\
\text { only } 3 \text { slides, in } 3 \mathrm{~min} \text { ) }\end{array}$ & NUI Galway & $\begin{array}{l}\text { Oct } \\
2015\end{array}$ \\
\hline 10. & $\begin{array}{l}\text { Re-thinking how we } \\
\text { deliver care to young } \\
\text { adults with type } 1 \text { diabetes } \\
\text { in primary and secondary } \\
\text { care }\end{array}$ & $\begin{array}{l}2 \text { YAP members were } \\
\text { invited speakers (with the } \\
\text { grant holder) }\end{array}$ & $\begin{array}{l}8^{\text {th }} \text { West of Ireland } \\
\text { Integrated Diabetes Care } \\
\text { Conference }\end{array}$ & $\begin{array}{l}\text { Connemara } \\
\text { Coast Hotel, } \\
\text { Galway }\end{array}$ & $\begin{array}{l}16-17 \\
\text { Oct } \\
2015\end{array}$ \\
\hline 11. & $\begin{array}{l}\text { Formation of a type } 1 \\
\text { diabetes young adult } \\
\text { panel }\end{array}$ & $\begin{array}{l}\text { Abstract that was co- } \\
\text { authored by all YAP } \\
\text { members was accepted } \\
\text { for poster presentation }\end{array}$ & $\begin{array}{l}7^{\text {th }} \text { West of Ireland } \\
\text { Integrated Diabetes Care } \\
\text { Conference }\end{array}$ & $\begin{array}{l}\text { Westport, } \\
\text { Co Mayo }\end{array}$ & $\begin{array}{l}3-4 \text { Oct } \\
2014\end{array}$ \\
\hline
\end{tabular}


intervention. The team plans to test this intervention in a feasibility and randomised pilot study prior to conducting a full scale definitive trial. It is the intention of the research team to establish two other YAPs in the other two proposed study locations.

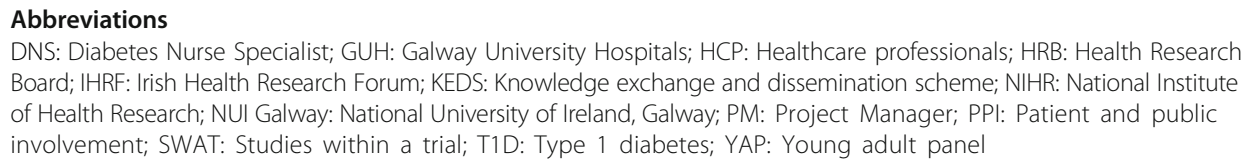
Board; IHRF: Irish Health Research Forum; KEDS: Knowledge exchange and dissemination scheme; NIHR: National Institute of Health Research; NUI Galway: National University of Ireland, Galway; PM: Project Manager; PPI: Patient and public involvement; SWAT: Studies within a trial; T1D: Type 1 diabetes; YAP: Young adult panel

\section{Acknowledgements}

This study was supported by the Health Research Board through a Health Research Award (HRA-2013-HSR-316). Two study steering group meetings were funded by Novo Nordisk Ireland, this included venue hire and catering costs only. The funders did not have a role in the design, collection, analysis, interpretation of data or the formation of the Young Adult Panel. The authors declare that they have no conflict of interest. The authors would like to acknowledge all members of the D1 Now Type 1 Diabetes Young Adult Study Group. Members of the Young Adult Panel previously presented this work as a poster presentation at the 7th West of Ireland Integrated Diabetes Care Conference, Westport, 3-4 October 2014 and at the NUI Galway Threesis Competition 2015.

\section{Funding}

Health Research Board (Ireland), Health Research Award (HRA-HSR-2013-316). The funders did not have a role in the design, collection, analysis, interpretation of data or the formation of the Young Adult Panel.

\section{Availability of data and materials}

Available upon request to corresponding author.

\section{Authors' contributions}

$\mathrm{MCOH}, \mathrm{SS}$ and $\mathrm{AC}$ participated in the design and formation of the Young Adult Panel. MCOH, AC, SS, LH, MOD, MB and SD drafted the manuscript. CK, GA, AC, CD, ML, MM, MM and GT contributed to drafting of the Plain English

Summary, they also read and approved the final manuscript.

\section{Ethics approval and consent to participate}

N/A.

\section{Consent for publication}

All authors consent for publication.

\section{Competing interests}

The authors declare that they have no competing interests.

\section{Publisher's Note}

Springer Nature remains neutral with regard to jurisdictional claims in published maps and institutional affiliations.

\section{Author details}

${ }^{1}$ Research \& Development, Health and Wellbeing Division, Health Service Executive, Merlin Park University Hospital, 2nd Floor, Block A, Merlin Park University Hospital, Galway H91 N973, Ireland. ${ }^{2}$ School of Medicine, National University of Ireland, Galway, Galway, Ireland. ${ }^{3}$ Centre for Diabetes, Endocrinology and Metabolism, Galway University Hospitals, Galway, Ireland. ${ }^{4}$ Member of the D1 Now Young Adult Panel, Galway, Ireland. ${ }^{5}$ Jigsaw, Galway, Ireland. ${ }^{6}$ Pediatric Psychology Lab, West Virginia University, Morgantown, West Virginia, USA. ${ }^{7}$ Health Behaviour Change Research Group, School of Psychology, Galway, Ireland.

Received: 3 February 2017 Accepted: 14 August 2017

Published online: 23 October 2017

\section{References}

1. International Diabetes Federation. IDF Diabetes Atlas. 7th ed. Brussels, Belgium: International Diabetes Federation; 2015.

2. Balfe M, Brugha R, Smith D, Sreenan S, Doyle F, Conroy R. Considering quality of care for young adults with diabetes in Ireland. BMC Health Serv Res. 2013;13(1):448.

3. Eiser C, Johnson B, Brierley S, Ayling K, Young V, Bottrell K, Whitehead V, Elliott J, Scott A, Heller S. Using the Medical Research Council framework to develop a complex intervention to improve delivery of care for young people with type 1 diabetes. Diabet Med. 2013;30(6):e223-8.

4. Arnett JJ. Emerging adulthood: a theory of development from the late teens through the twenties. Am Psychol. 2000;55(5):469-80.

5. Hynes L, Byrne M, Dinneen SF, McGuire BE, O'Donnell M, MC SJ. Barriers and facilitators associated with attendance at hospital diabetes clinics among young adults (15-30 years) with type 1 diabetes mellitus: a systematic review. Pediatr Diabetes. 2016;17(7):509-18.

6. Bryden KS, Peveler RC. Stein a, al. e. Clinical and psychological course of diabetes form adolescence to young adulthood: a longitudinal cohort study. Diabetes Care. 2001;24:1536-40. 
7. Johnson B, Elliott J, Scott A, Heller S, Eiser C. Medical and psychological outcomes for young adults with type 1 diabetes: no improvement despite recent advances in diabetes care. Diabet Med. 2014;31(2):227-31.

8. McKnight JA, Wild SH, Lamb MJ, Cooper MN, Jones TW. Al. E. Glycaemic control of type 1 diabetes in clinical practice early in the 21st century: an international comparison. Diabet Med. 2015;32(8):1036-50.

9. O' Hara MC, Hynes L, O'Donnell M, Nery N, Byrne M, Heller SR and Dinneen SF, for the Irish Type 1 Diabetes Young Adult Study Group. A systematic review of interventions to improve outcomes for young adults with type 1 diabetes: Towards the development of a new intervention. Diabetic Medicine. 20 Oct 2016 [Epub ahead of print], doi:10.1111/dme.13276.

10. Wilson P, Mathie E, Keenan J, McNeilly E, Goodman C, Howe A, Polan F, Staniszewska S, Kendall S, Munday D, Cowe M, Peckham S. ReseArch with Patient and Public invOlvement: a RealisT evaluation - the RAPPORT study. Health Services and Delivery Research. 2015;3(38) doi:10.3310/hsdr03380.

11. Domecq JP, Prutsky G, Elraiyah T, Wang Z, Nabhan M, Shippee N, et al. Patient engagement in research: a systematic review. BMC Health Serv Res. 2014;14:89.

12. Selby JV, Beal AC, Frank L. The Patient-Centered Outcomes Research Institute (PCORI) national priorities for research and initial research agenda. JAMA. 2012;307(15):1583-4.

13. O'Haire C, McPhetters M, Nakamoto E, LaBrant L, Most C, Lee K, Graham E, Cottrell E, Guise JM. Methods Future Research Needs Reports, No. 4. In: Engaging stakeholders to identify and prioritize future research needs. (US), MD, USA: Agency for Healthcare Research and Quality; 2011. https://www.ncbi.nlm.nih.gov/books/NBK62565/. Accessed 15 Aug 2017.

14. Bruni RA, Laupacis A, Martin DK. Or the University of Toronto Priority setting in health care research group. Public engagement in setting priorities in health care. Can Med Assoc J. 2008;179(1):15-8.

15. Saunders $C$ and Girgis A. Status, challenges and facilitators of consumer involvement in Australian health and medical research. Health Research Policy and Systems 2010, 8:34 doi:10.1186/1478-4505-8-34.

16. INVOLVE, the national advisory group of the National Institute for Health Research in the UK. http://www.invo.org uk/. Accessed 15 Aug 2017

17. National Institute for Health Research. Going the Extra Mile: Improving the Nation's Health and Wellbeing through Public Involvement in Research. 2015; http://www.nihr.ac.uk/about-us/documents/Extra\%20Mile2.pdf. Accessed 15 Aug 2017.

18. Andrews $L M$, Allen $H$, Sheppard ZA, Baylis G, Wainwright TW. More than just ticking a box... how patient and public involvement improved the research design and funding application for a project to evaluate a cycling intervention for hip osteoarthritis. Research Involvement and Engagement. 2015;1:13.

19. Tait L, Lester H. Encouraging user involvement in mental health services. Advances in Psychiatric Treatment Apr. 2005;11(3):168-75.

20. Crocker J, Rees S, Locock L, Petit-Zeman S, Chant A, Treweek S, Cook J, Farrar N, Woolfall K, Bulbulia R. Developing a patient and public involvement intervention to enhance recruitment and retention in surgical trials (PIRRIST): study protocol. Trials. 2015;16(Suppl 2):89.

21. Bagley HJ, Short H, Harman NL, Hickey HR, Gamble CL, Woolfall K, Young B, Williamson PR. A patient and public involvement (PPI) toolkit for meaningful and flexible involvement in clinical trials - a work in progress. Research Involvement and Engagement. 2016;2:15.

22. Staley K. Exploring impact: public involvement in NHS, public health and social care research. Eastleigh: INVOLVE; 2009.

23. Boote JD, Twiddy M, Baird W, Birks Y, Clarke C, Beever D. Supporting public involvement in research design and grant development: a case study of a public involvement award scheme managed by a National Institute for Health Research (NIHR) research design service (RDS). Health Expect. 2013;18(5):1481-93.

24. Buck D, Gamble C, Dudley L, Preston J, Hanley B, Williamson PR, Young B, for the EPIC patient advisory group. From plans to actions in patient and public involvement: qualitative study of documented plans and the accounts of researchers and patients sampled from a cohort of clinical trials BMJ Open 2014, 4:e006400. doi:10.1136/bmjopen2014-006400

25. Health Research Board (HRB) Strategy 2016-2020. Research. Evidence. Action. http://www.hrb.ie/publications/hrbpublication/publications//702/. Accessed 15 Aug 2017.

26. Health Research Board (HRB) Grants and Fellowships. PPI Ignite Awards 2017 - Supporting public and patient involvement in research. Infrastructure and Special Initiatives. http://www.hrb.ie/research-strategy-funding/grantsand-fellowships/hrb-grants-and-fellowships/grant/161/. Accessed 15 Aug 2017.

27. Irish Health Research Forum. Document on: public and patient involvement (PPI) in research (April 2015). http:// media.wix.com/ugd/75eae6_4bcbe2242ac14cad898047df445dcb92.pdf. Accessed 15 Aug 2017.

28. Coyne I, Harder M. Children's participation in decision-making: balancing protection with shared decision-making using a situational perspective. Journal of Child Health Care. 2011;15(4):312-9.

29. Coad J, Flay J, Aspinall M, Bilverstone B, Coxhead E, Hones B. Evaluating the impact of involving young people in developing children's services in an acute hospital trust. J Clin Nurs. 2008;17:3115-22.

30. Department of Children and Youth Affairs (2015). National Strategy on Children and Young People's Participation in Decision-making, 2015-2020. Dublin: Government Publications. Available at: https://www.dcya.gov.ie/viewdoc. asp?fn=\%2Fdocuments\%2FNationalChildrensStrategy 15-20\%2Fparticipationstrategy.htm\&mn=chiw9h\&nID=1. Accessed 15 Aug 2017.

31. Shaw C, Brady LM, Davey C. Guidelines for research with children and young people, NCB research Centre, 2011. London: National Children's Bureau; 2011.

32. Royal College of Paediatrics and Child Health and Young Persons Health Special Interest Group. Not Just a Phase - A Guide to the Participation of Children and Young People in Health Services. London: RCPCH; 2010.

33. McDonagh JE, Bateman B. Nothing about us without us. Research involving young people. Arch Dis Child Educ Pract Ed. 2012;97:55-60.

34. Craig P, Dieppe P, Macintyre S, Michie S, Nazareth I, Petticrew M. Developing and evaluating complex interventions: the new Medical Research Council guidance. Int J Nurs Stud. 2013;50(5):587-92.

35. Michie S, van Stralen MM, West R. The behaviour change wheel: a new method for characterising and designing behaviour change interventions. Implement Sci. 2011;6:42.

36. Jigsaw G. https://www.jigsaw.ie/jigsaw_galway/. Accessed 15 Aug 2017. 
37. Illback RJ, Bates T, Hodgens C, Galligan K, Smith P, Sanders D, Dooley B. Jigsaw: engaging communities in the development and implementation of youth mental health services and supports in the Republic of Ireland. J Ment Health. 2010;19(5):422-35.

38. Fitzmaurice J. Jigsaw overview of Galway's system for promoting mental health in young people. Nursing in General Practice, 2012, Mental Health - Part 1:26-29.

39. Ryan M, Gerard K, Amaya-Amaya M, editors. Using discrete choice experiments to value health and health care, vol. 11: Springer Science \& Business Media; 2007, Springer Netherlands.

40. Charters E. The use of think-aloud methods in qualitative research an introduction to think-aloud methods. Brock Education Journal. 2003;12(2):68-82.

41. National Institute for Health and Care Excellence. Patient and Public Involvement Policy. https://www.nice.org.uk/ media/default/About/NICE-Communities/Public-involvement/Patient-and-public-involvement-policy/Patient-andpublic-involvement-policy-November-2013.pdf. Accessed 15 Aug 2017.

42. West of England Academic Health Science Network. Working Together: A toolkit for health professionals on how to involve the public. http://www.weahsn.net/wp-content/uploads/PPI_Toolkit.pdf. Accessed 15 Aug 2017.

43. Scholes C, Mandleco B, Roper S, Dearing K, Dyches T, Freeborn D. A qualitative study of young people's perspectives of living with type 1 diabetes: do perceptions vary by levels of metabolic control? J Adv Nurs. 2013; 69(6):1235-47.

44. Domecq JP, Prutsky G, Elraiyah T, Wang Z, Nabhan M, Shippee N, Brito JP, Boehmer K, Hasan R, Firwana B, Erwin P, Eton D, Sloan J, Montori V, Asi N, Dabrh AM, Murad MH. Patient engagement in research: a systematic review. BMC Health Serv Res. 2014;14:89.

45. Schmittdiel JA, Desai J, Schroeder EB, Paolino AR, Nichols GA, Lawrence JM, O'Connor PJ, Ohnsorg KA, Newton KM, Steiner JF. Methods for engaging stakeholders in comparative effectiveness research: a patient-centered approach to improving diabetes care. Healthcare. 2015;3(2):80-8.

46. Supple D, Roberts A, Hudson V, Masefield S, Fitch N, Rahmen M, Flood B, de Boer W, Powell P, Wagers S, on behalf of the U-BIOPRED PIP Group. From tokenism to meaningful engagement: best practices in patient involvement in an EU project Research Involvement and Engagement 2015; 1:15.

47. Mockford C, Murray M, Seers K, Oyebode J, Grant R, Boex S, Staniszewska S, Diment Y, Leach J, Sharma U, Clarke R, Suleman R. A SHARED study-the benefits and costs of setting up a health research study involving lay co-researchers and how we overcame the challenges. Research Involvement and Engagement. 2016;2:8.

48. Brett J, Staniszewska S, Mockford C, Herron-Marx S, Hughes J, Tysall C, Suleman R. Mapping the impact of patient and public involvement on health and social care research: a systematic review. Health Expect. 2014;17(5):637-50.

\section{Submit your next manuscript to BioMed Central and we will help you at every step:}

- We accept pre-submission inquiries

- Our selector tool helps you to find the most relevant journal

- We provide round the clock customer support

- Convenient online submission

- Thorough peer review

- Inclusion in PubMed and all major indexing services

- Maximum visibility for your research

Submit your manuscript at www.biomedcentral.com/submit 